\title{
$\alpha$ CaMKII Autophosphorylation Controls the Establishment of Alcohol Drinking Behavior
}

\author{
Alanna C Easton', Walter Lucchesi ${ }^{2}$, Anbarasu Lourdusamy', Bernd Lenz ${ }^{3}$, Jalal Solati ${ }^{4,5}$, Yulia Golub ${ }^{4}$, \\ Piotr Lewczuk ${ }^{3}$, Cathy Fernandes', Sylvane Desrivieres', Ralph R Dawirs', Gunther H Moll, \\ Johannes Kornhuber ${ }^{3}$, Josef Frank ${ }^{6}$, Per Hoffmann 7 , Michael Soyka ${ }^{8}$, Falk Kiefer', The GESGA Consortium, \\ Gunter Schumann', K Peter Giese ${ }^{2}$ and Christian P Müller*, 1,3 \\ 'MRC Social, Genetic and Developmental Psychiatry Research Centre, Institute of Psychiatry, King's College London, London, UK; ${ }^{2}$ Centre for the \\ Cellular Basis of Behavior, MRC Centre for Neurodegeneration Research, Institute of Psychiatry, King's College London, James Black Centre, \\ London, UK; ${ }^{3}$ Department of Psychiatry and Psychotherapy, Friedrich-Alexander-University of Erlangen-Nuremberg, Erlangen, Germany; \\ ${ }^{4}$ Department of Child and Adolescent Mental Health, University Clinic Erlangen, Erlangen, Germany; ${ }^{5}$ Department of Biology, Faculty of Science, \\ Islamic Azad University, Karaj, Iran; ' Department of Genetic Epidemiology in Psychiatry, Central Institute of Mental Health, Medical Faculty \\ Mannheim, Heidelberg University, Mannheim, Germany; ${ }^{7}$ Institute of Human Genetics, Life \& Brain Center, University of Bonn, Bonn, Germany; \\ ${ }^{8}$ Psychiatric Hospital, University of Munich, Munich, Germany; ${ }^{9}$ Department of Addictive Behaviour and Addiction Medicine, Central Institute of \\ Mental Health, Medical Faculty Mannheim, Heidelberg University, Mannheim, Germany
}

The $\alpha$ - $\mathrm{Ca}^{2+} /$ calmodulin-dependent protein kinase $\|(\alpha \mathrm{CaMKII})$ is a crucial enzyme controlling plasticity in the brain. The autophosphorylation of $\alpha$ CaMKII works as a 'molecular memory' for a transient calcium activation, thereby accelerating learning. We investigated the role of $\alpha$ CaMKII autophosphorylation in the establishment of alcohol drinking as an addiction-related behavior in mice. We found that alcohol drinking was initially diminished in $\alpha$ CaMKII autophosphorylation-deficient $\alpha$ CaMKII ${ }^{\text {T286A }}$ mice, but could be established at wild-type level after repeated withdrawals. The locomotor activating effects of a low-dose alcohol $(2 \mathrm{~g} / \mathrm{kg})$ were absent in $\alpha$ CaMKII ${ }^{\text {T286A }}$ mice, whereas the sedating effects of high-dose $(3.5 \mathrm{~g} / \mathrm{kg})$ were preserved after acute and subchronic administration. The in vivo microdialysis revealed that $\alpha \mathrm{CaMKII}{ }^{\top 286 \mathrm{~A}}$ mice showed no dopamine (DA) response in the nucleus accumbens to acute or subchronic alcohol administration, but enhanced serotonin (5-HT) responses in the prefrontal cortex. The attenuated DA response in $\alpha \mathrm{CaMKII}{ }^{\text {T286A }}$ mice was in line with altered c-Fos activation in the ventral tegmental area after acute and subchronic alcohol administration. In order to compare findings in mice with the human condition, we tested 23 single-nucleotide polymorphisms (SNPs) in the CAMK2A gene for their association with alcohol dependence in a population of I 333 male patients with severe alcohol dependence and 939 controls. We found seven significant associations between CAMK2A SNPs and alcohol dependence, one of which in an autophosphorylation-related area of the gene. Together, our data suggest $\alpha$ CaMKII autophosphorylation as a facilitating mechanism in the establishment of alcohol drinking behavior with changing the DA-5-HT balance as a putative mechanism.

Neuropsychopharmacology (2013) 38, 1636-1647; doi:I0.1038/npp.2013.60; published online 27 March 2013

Keywords: $\alpha$ CaMKIll; autophosphorylation; alcohol; reinforcement; dopamine; serotonin

\section{INTRODUCTION}

Alcohol use can develop into addiction in a significant number of people, and yet the mechanism of transition between alcohol use and dependence is not sufficiently understood. The establishment of addiction remains largely unknown but it is thought to involve a number of distinct learning and memory processes. It is now widely believed that addiction and memory formation share molecular and

*Correspondence: Professor CP Müller, Section of Addiction Medicine, Department of Psychiatry and Psychotherapy, FriedrichAlexander-University of Erlangen-Nuremberg, Schwabachanlage 6, Erlangen 91054, Germany, Tel: + 49 9131 85 36896, Fax: +49 9131 85 36002, E-mail: Christian.Mueller@uk-erlangen.de Received 19 October 2012; revised 22 January 2013; accepted 4 February 2013; accepted article preview online 4 March 2013 anatomical pathways (Nestler, 2002; Kelley, 2004; Müller and Schumann, 2011).

$\mathrm{Ca}^{2+} /$ calmodulin-dependent protein kinase II (CaMKII) plays a key role in the plasticity of glutamatergic postsynapses of the brain (Colbran and Brown, 2004; Irvine et al, 2006; Lamsa et al, 2007; Wayman et al, 2008) and appears crucial for learning and memory, with the $\alpha$-subunit-composed heteromer ( $\alpha \mathrm{CaMKII})$ being the most influential (Elgersma et al, 2004; Easton et al, 2012). There is considerable evidence for a role of CaMKII in drug addiction in humans (Li et al, 2008) and in animal models (Pierce et al, 1998; Tan, 2002; Licata and Pierce, 2003; Sakurai et al, 2007; Choe and Wang, 2002). In particular, CaMKII levels in the ventral tegmental area (VTA) and nucleus accumbens (NAcc) appear of crucial importance for psychostimulant sensitization, place preference, and 
self-administration (Licata et al, 2004; Anderson et al, 2008; Kourrich et al, 2012). Although little is known about the role in alcohol addiction, alcohol affects CaMKII levels in the brain (Smith and Navratilova, 1999; McBride et al, 2009; Mahadev et al, 2001; Lee et al, 2011) and increases phosphorylation rate at Thr286 (Garic et al, 2011; Wang et al, 2012). Both may control alcohol effects on cellular signaling (Liu et al, 2006; Xu et al, 2008), behavior (Kim et al, 2012; Wang et al, 2012), and neurotoxicity (Garic et al, 2011).

Following transient calcium/calmodulin activation, $\alpha$ CaMKII can switch to an autonomous mode of activity known as autophosphorylation. Mice with a point mutation in position 286 of the protein $\left(\alpha \mathrm{CaMKII}^{\mathrm{T} 286 \mathrm{~A}}\right)$ do not show autophosphorylation, but severe learning impairments (Giese et al, 1989; Irvine et al, 2005) and emotional dysregulation (Easton et al, 2011), suggesting that autophosphorylation controls, in particular, the speed of learning but not the capacity to learn or memory retrieval (Irvine et al, 2006).

Alcohol exerts its effects at the interface of the glutamatergic and monoaminergic systems, which in turn shape behavioral effects and addiction development (McBride, 2010; Spanagel, 2009). Here we asked whether $\alpha$ CaMKII autophosphorylation plays a role in the establishment of alcohol drinking behavior as a crucial component of (later) addiction development. We hypothesized that a genetically induced deficiency in $\alpha$ CaMKII autophosphorylation results in slower establishment of alcohol drinking in mice, which would make their drinking phenotype initially different from wild-type controls. With increasing learning experience, for example, after $\geqslant 5$ learning trials (Irwine et al, 2005), which we considered as a subchronic exposition, they should approach the wild-type drinking phenotype. In parallel, different effects on neuronal mechanisms, such as dopamine (DA) and serotonin (5-HT) responses and cellular activation in the VTA, should occur after acute or subchronic alcohol exposure (Smith and Navratilova, 1999). Furthermore, we asked whether single-nucleotide polymorphisms (SNPs) related to $\alpha \mathrm{CaM}$ KII function should change the risk for alcohol addiction in humans.

\section{MATERIALS AND METHODS}

\section{Animals}

Male and female $\alpha$ CaMKII ${ }^{\mathrm{T} 286 \mathrm{~A}}$ mutant mice (Giese et al, 1989) were studied in gender-balanced designs in all experiments (MT, $n=50$; heterozygous (Het), $n=43$, wild-type (WT), $n=52$; for details, see Supplementary Information). This mutation blocks the autophosphorylation of CaMKII but does not affect the $\mathrm{Ca}^{2+}$-dependent activity. Animals were individually housed, provided with food and water ad libitum, and kept on a 12:12 h light/ dark cycle (lights on at $0700 \mathrm{~h}$ ). Behavioral tests were performed during the light cycle between 0900 and $1600 \mathrm{~h}$. Room temperature was maintained between 19 and $22^{\circ} \mathrm{C}$ at a humidity of $55 \%( \pm 10 \%)$. All housing and experimental procedures were performed in accordance with the UK Home Office Animals (Experimental Procedures) Act 1986.

\section{Alcohol Drinking and Alcohol Deprivation Effect}

Alcohol drinking was tested in naive $\alpha \mathrm{CaMKII}^{\mathrm{T} 286 \mathrm{~A}}$ (MT; $n=10)$, WT $(n=12)$ and Het $(n=12)$ animals using a twobottle free-choice drinking paradigm. Each cage was equipped with two bottles constantly available, one of which contained tap water and the other contained alcohol in various concentrations. After an acclimatization period to establish a drinking baseline, animals received alcohol at increasing concentrations of $2,4,8$, and $12 \mathrm{vol} . \%$. Mice were exposed to each concentration of alcohol for 4 days. Thereafter, alcohol concentration was switched to 16 vol.\% and animals were allowed to drink for 2 weeks. In order to measure the alcohol deprivation effect (Spanagel and Hölter, 2000), baseline consumption of 16 vol.\% alcohol was measured. Alcohol was removed for 3 weeks (both bottles now containing tap water) before it was re-introduced for 4 days. This procedure was repeated once more. Bottles were changed and weighed daily. The consumed amount of alcohol relative to body weight and the preference $v s$ water were measured.

\section{Taste Preference Test}

Alcohol-experienced animals were used for this test (MT: $n=10$; WT: $n=12$; Het: $n=12)$. Sucrose $(0.45$ and $5 \%)$ and quinine $(10$ and $20 \mathrm{mg} / \mathrm{dl})$ preference was measured in a two-bottle free-choice test $v s$ water. Each dose was offered for 3 days with the position of the bottles being changed and weighed daily (Spanagel et al, 2005).

\section{Determination of Blood Alcohol Levels}

Alcohol-naive animals were used for this test (MT: $n=11$; WT: $n=12$; Het: $n=14)$. Animals were injected intraperitoneally (i.p.) with alcohol $(3.5 \mathrm{~g} / \mathrm{kg})$. Mice were left undisturbed and then systematically culled at 15, 30, and $60 \mathrm{~min}$ after injection. Animals were immediately killed by cervical dislocation and trunk blood was collected. Blood was left at room temperature for $30-60 \mathrm{~min}$ to allow clotting. The blood was then placed in a centrifuge for $10-15 \mathrm{~min}$ at $3000-4000$ r.p.m. at room temperature and the supernatant aspirated. Serum samples were then stored at $-80^{\circ} \mathrm{C}$ waiting further analysis. Analysis of the alcohol concentration in the serum samples was performed with quantitative enzymatic method (for details, see Supplementary Information).

\section{Loss of Righting Reflex (LORR)}

Alcohol-naive animals were used for this test (MT: $n=5$; WT: $n=5$; Het: $n=5)$. Animals were administered with an alcohol injection of $3.5 \mathrm{~g} / \mathrm{kg}$ (i.p.) (Spanagel et al, 2002) to induce LORR, and immediately placed in an empty cage. LORR was observed when the animal becomes ataxic and stopped moving for at least $30 \mathrm{~s}$. The animal was then placed on its back. Recovery from alcohol administration was defined as the animal being able to right itself three times within a minute. A 2-h cutoff was used. Time taken for the animal to lose its righting reflex, and time to recovery from alcohol's effect were recorded. LORR was carried out on 
day 1 of the experiment. Upon completion of the trial, the animal was returned to the home cage. Alcohol was then administered once daily on days $2-7$, when animals were weighed and injected $2 \mathrm{~g} / \mathrm{kg}$ (i.p.). LORR was again tested on day 8 of the experiment when animals received $3.5 \mathrm{~g} / \mathrm{kg}$ (i.p.) alcohol.

\section{In Vivo Microdialysis}

Mice were deeply anesthetized and two guide cannulas were aimed at the prefrontal cortex (PFC) and the NAcc (Franklin and Paxinos, 1997). Animals were allowed at least 5 days for complete recovery before microdialysis testing (for details, see Supplementary Information).

On the day of the experiment, microdialysis probes with membrane lengths of $2 \mathrm{~mm}$ for the PFC (MAB 6.14.2.) and $1 \mathrm{~mm}$ (MAB 6.14.1.) for the NAcc were inserted into the guide cannulae under a short $(3-5 \mathrm{~min})$ isoflurane anesthesia and perfused with artificial cerebrospinal fluid (aCSF). After probe insertion, the animal was placed into an open field $(21 \times 21 \times 30 \mathrm{~cm})$ of a TruScan system (Coulbourn Instruments, Allentown, PA). Food and water were provided ad libitum and room temperature maintained between 19 and $22{ }^{\circ} \mathrm{C}$. Samples were collected every $20 \mathrm{~min}$. Three samples were taken as baseline and the neurotransmitters DA, 5-HT and NA were quantified by HPLC-EC as described previously (Müller et al, 2007; Pum et al, 2007). An injection of alcohol was then administered i.p. $(2 \mathrm{~g} / \mathrm{kg})$ and further nine samples were collected. Locomotor activity was automatically measured by a TruScan system parallel to neurochemical activity. Locomotion was assessed as units in 20-min intervals.

Alcohol-naive animals were used for this test (MT: $n=12$; WT: $n=11$; Het: $n=12$ ). The in vivo microdialysis was carried out on day 1 of the experiment when animals received the first of eight alcohol injections ( $2 \mathrm{~g} / \mathrm{kg}$, i.p.). A smaller locomotor stimulating dose of alcohol was used here and in the subsequent experiment to allow for behavioral sensitization/tolerance effects to be observed. After the microdialysis trial was completed, the animal was anesthetized using isoflurane. The probes were removed and guides re-inserted. Alcohol was then administered once daily on days $2-7(2 \mathrm{~g} / \mathrm{kg}$, i.p. $)$. The in vivo microdialysis was carried out again on day 8 of the experiment, providing a subchronic neurochemical and behavioral response to alcohol treatment. Once microdialysis experiments were complete, animals were killed by cervical dislocation. Brains were fixed in $4 \%$ formaldehyde solution and stored at $4{ }^{\circ} \mathrm{C}$. Brains were sliced on a microtome and stained with cresyl violet for verification of probe placement.

\section{c-Fos Activation after Acute and Subchronic Alcohol Treatment}

Alcohol-naive animals were used for this test (MT: $n=12$; WT: $n=12$ ). Animals were transferred from the home cage to a temporary cage and injected either once (acute) or on seven consecutive days (subchronic) with alcohol at a dose of $2 \mathrm{~g} / \mathrm{kg}$ (i.p.). Mice were left undisturbed for $70 \mathrm{~min}$ after injection. Thereafter, mice were culled under isoflurane narcosis and transcardially perfused. Brains were taken and c-Fos activation was measured in the rostral and caudal VTA (for details, see Supplementary Information).

\section{Genetic Association in a Human Sample}

Genotype data were extracted from a previously performed genome-wide association study (Treutlein et al, 2009; Frank et al, 2012). In brief, the sample comprised $n=1333$ male patients with severe DSM-IV alcohol dependence and $n=939$ male controls. Individuals were genotyped using Illumina infinium assays. From the autosomal SNPs available, we selected only those located within the transcript region of the CAMK2A gene, resulting in a set of 23 SNPs. We used Armitage trend tests to assess associations of CAMK2A SNPs with alcohol dependence. Analysis of linkage disequilibrium (LD) structure and haplotype association testing was performed using haploview version 4.2 (http://www.broad.mit.edu/mpg/haploview/). Haplotype blocks were defined according to the method of Gabriel et al (2002). All $P$-values were corrected using the false discovery rate (FDR) procedure (Benjamini and Hochberg, 1995).

\section{Statistical Analysis}

All quantitative data were expressed as mean \pm SEM. Data were analyzed using ANOVAs (for repeated measures where appropriate) followed by preplanned comparisons using Fisher's LSD tests (Szumlinski et al, 2005). For experimentspecific details, see Supplementary Information. Although sex differences are well known in alcoholism-related behaviors (Lenz et al, 2012), we did not see significant sex differences in this study. Therefore, data were collapsed for analysis. The softwares SPSS 17.0, PLINK v1.07, and Statistica 9 were used. A significance level of $P<0.05$ was used.

\section{RESULTS}

\section{Reduced Alcohol Preference}

In order to test a potential involvement of $\alpha$ CaMKII autophosphorylation in the establishment of alcohol drinking behavior, we measured drinking in a two-bottle freechoice paradigm. We found that $\alpha \mathrm{CaMKII}^{\mathrm{T} 286 \mathrm{~A}}$ and Het animals drank significantly less alcohol than WT animals (Figure 1a; two-way ANOVA, genotype: $\mathrm{F}_{2,124}=11.17$, $P<0.0001$; dose: $F_{3,124}=55.10 ; P<0.0001$; interaction: $\left.\mathrm{F}_{6,124}=2.04, \quad P=0.065\right)$. Pairwise comparisons showed significant differences between $\alpha \mathrm{CaMKII}^{\mathrm{T} 286 \mathrm{~A}}$ and $\mathrm{WT}$ animals at 8 vol.\% (LSD, $P=0.016$ ) and 12 vol.\% $(P<0.0001)$. Also, Het alcohol consumption was reduced $v s \mathrm{WT}$ at 12 vol.\% $(P=0.0002)$. Alcohol preference $v s$ water was significantly reduced in $\alpha$ CaMKII ${ }^{\mathrm{T} 286 \mathrm{~A}}$ compared with WT animals (Figure 1b; two-way ANOVA, genotype: $\mathrm{F}_{2,124}=5.74, P=0.0041$; dose: $\left.\mathrm{F}_{3,124}=19.94, P<0.0001\right)$. Pairwise comparisons showed a significant difference between $\alpha$ CaMKII ${ }^{\mathrm{T} 286 \mathrm{~A}}$ and $\mathrm{WT}$ animals at 4 vol.\% $(P=0.022)$ and a trend at 12 vol.\% $(P<0.058)$. These findings suggest that $\alpha \mathrm{CaMKII}$ autophosphorylation is 
a

Alcohol consumption

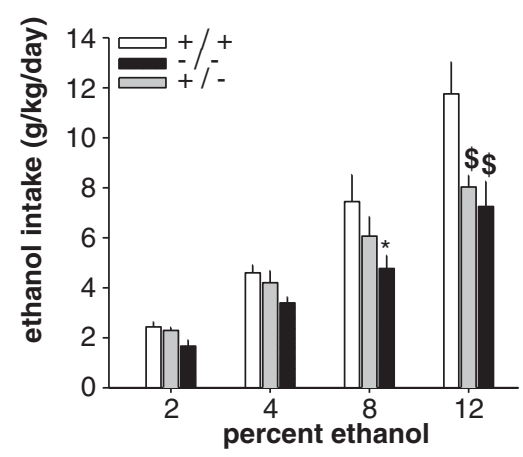

C
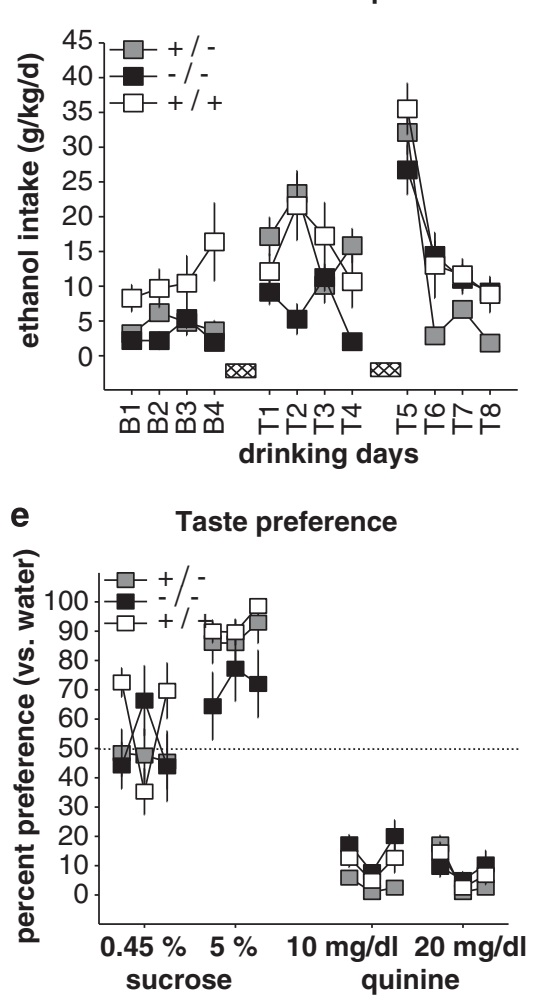

b Alcohol preference

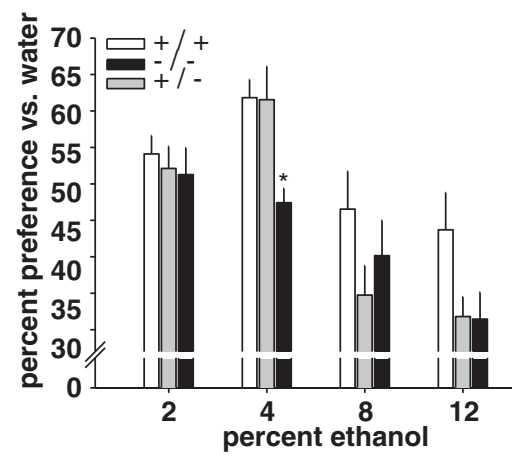

d $\quad$ ADE preference

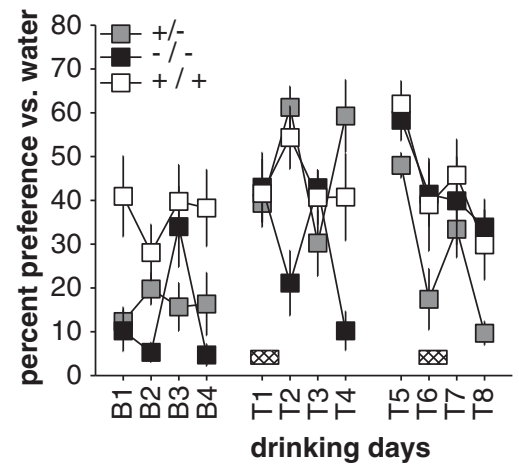

f Blood alcohol level

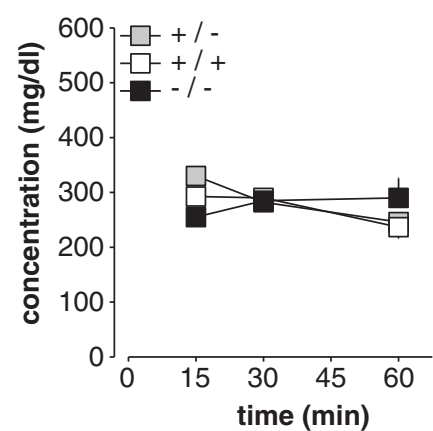

Figure I $\alpha$ CaMKII autophosphorylation-deficient mice initially drink less alcohol but reach wild-type (WT) level after repeated withdrawal. They show a largely preserved taste preference and avoidance and comparable alcohol bioavailability. (a) Alcohol consumption shown as mean consumption ( \pm SEM) over 4 days of drinking for each dose of alcohol. (b) Alcohol preference ( \pm SEM) vs water shown as mean preference ( \pm SEM) over 4 days of drinking for each dose of alcohol. (c) Mean consumption ( \pm SEM) of a 16 vol.\% alcohol solution per day. Alcohol deprivation effect on consumption after two 3-week withdrawal periods (hatched bars; BI-B4-baseline). Alcohol consumption increased in the $\alpha$ CaMKII ${ }^{\text {T286A }}$ and Het animals over 4 days after the first 3-week withdrawal (TI-T4). $\alpha$ CaMKII ${ }^{\text {T286A }}$ but not Het consumption was still below WT levels. After the second 3-week withdrawal period, consumption increased in all animals, suggesting an ADE (T5-T8), with the $\alpha$ CaMKII ${ }^{\text {T286A }}$ then consuming at the same level as WT animals. (d) Mean preference vs water ( \pm SEM) of a 16 vol.\% alcohol solution per day. Alcohol deprivation effect on preference after two 3-week withdrawal periods (hatched bars). (e) Mean preference of sucrose and quinine solution over water measured over 3 consecutive days, respectively. (f) Blood alcohol levels (mean \pm SEM) after a $3.5 \mathrm{~g} / \mathrm{kg}$ (i.p.) injection of alcohol (*P $<0.05,{ }^{\$} P<0.001$ vs WT).

required for full establishment of alcohol drinking and alcohol preference over water in a standard drinking test.

\section{Repeated Withdrawal Eliminates Preference Differences}

Initial alcohol preference was reduced in $\alpha \mathrm{CaMKII}^{\mathrm{T} 286 \mathrm{~A}}$ mice. We now investigated whether this initial difference could be overcome by repeated exposition/withdrawal from alcohol in a similar way at it was observed in nondrug-motivated learning tasks (Irvine et al, 2005). Voluntary alcohol consumption is known to escalate after repeated withdrawal periods, which is known as the alcohol deprivation effect (ADE; Spanagel and Hölter, 2000). We found that $\alpha$ CaMKII ${ }^{\mathrm{T} 286 \mathrm{~A}}$ as well as Het animals consumed significantly less alcohol during a 4-day baseline when offered a 16 vol.\% alcohol solution (Figure 1c; B1-B4, twoway ANOVA, genotype: $\mathrm{F}_{2,124}=11.67, P<0.0001$ ). Pairwise comparisons $v s$ WT on the factor genotype confirmed this 
(LSD; MT: $P<0.0001$; Het: $P<0.0001)$. Also, alcohol preference $v s$ water was altered in $\alpha \mathrm{CaMKII}^{\mathrm{T} 286 \mathrm{~A}}$ and Het animals during baseline (Figure 1d; B1-B4, two-way ANOVA, genotype: $\left.\mathrm{F}_{2,124}=15.15, P<0.0001\right)$. Pairwise comparisons on the factor genotype showed a reduction for $\alpha$ CaMKII $^{\text {T286A }}(P<0.0001)$ and Het animals $(P<0.0001)$ $v s$ WT. Alcohol consumption increased in the $\alpha \mathrm{CaMKII}^{\mathrm{T} 286 \mathrm{~A}}$ and Het animals over 4 days after the first 3-week withdrawal (T1-T4, two-way ANOVA, genotype: $\mathrm{F}_{2,124}=10.40, \quad P<0.0001$; time: $\mathrm{F}_{3,124}=2.59 ; \quad P=0.056$; interaction: $\left.\mathrm{F}_{6,124}=2.20, P=0.048\right)$. However, in $\alpha \mathrm{CaMKII}^{\mathrm{T} 286 \mathrm{~A}}$ $(P=0.0006)$ but not Het $(P>0.05)$ animals, consumption was still below WT levels. Also, alcohol preference $v s$ water increased during this interval (T1-T4, two-way ANOVA, genotype $\mathrm{F}_{2,124}=7.20, P<0.001$; interaction: $\mathrm{F}_{6,124}=4.80$, $P=0.0002)$. Preference was still lower in $\alpha \mathrm{CaMKII}^{\mathrm{T} 286 \mathrm{~A}}$ $(P=0.007)$ but not Het animals $(P>0.05)$, compared with WT animals. After the second 3-week withdrawal period, consumption increased temporarily in all animals (T5-T8, two-way ANOVA, genotype: $\mathrm{F}_{2,124}=6.08, P=0.003$; time: $\left.\mathrm{F}_{3,124}=52.59 ; P<0.0001\right)$, suggesting a clear ADE with the $\alpha \mathrm{CaMKII}^{\mathrm{T} 286 \mathrm{~A}}$ then consuming at the same level as WT animals $(P>0.05)$. Whereas the ADE was comparable between all genotypes on day 1 of reinstatement of alcohol drinking, it decreased stronger in the Het animals thereafter (vs WT, $P=0.0018$ ). This was also reflected in alcohol preference (T5-T8, two-way ANOVA; genotype: $\mathrm{F}_{2,124}=7.67, P=0.0007$; time: $\left.\mathrm{F}_{3,124}=10.83 ; P<0.0001\right)$, with $\alpha$ CaMKII $^{\mathrm{T} 286 \mathrm{~A}}$ preference at the same level as WT animals $(P>0.05)$. These data suggest that the reduced alcohol preference in $\alpha \mathrm{CaMKII}^{\mathrm{T} 286 \mathrm{~A}}$ mice can be overcome by repeated withdrawal.

\section{Sucrose Preference}

We found no genotype difference in the preference of $0.45 \%$ sucrose (Figure 1e; $P>0.05$ ). However, a 5\% sucrose solution was less preferred by the $\alpha \mathrm{CaMKII}^{\mathrm{T} 286 \mathrm{~A}}$ but not Het mice (genotype: $\mathrm{F}_{2,93}=6.20, P=0.003$; LSD vs WT,
$P=0.002)$. Quinine was avoided by all mice. The $10 \mathrm{mg} / \mathrm{dl}$ concentration was avoided most by Het animals (two-way ANOVA, genotype: $\mathrm{F}_{2,93}=10.38, \quad P<0.0001$; time: $\left.\mathrm{F}_{2,93}=5.25 ; \quad P=0.007\right)$, which differed from WT $(P<0.014)$. There was no genotype difference in the avoidance of a $20 \mathrm{mg} / \mathrm{dl}$ quinine solution $(P>0.05)$. These data suggest that although taste sensitivity is not disturbed by $\alpha$ CaMKII autophosphorylation deficiency, it may, nevertheless, slightly reduce preference of sweet solutions at higher concentrations.

\section{No Effects on Alcohol Bioavailability}

There was no significant difference in alcohol bioavailability between genotypes after a $3.5 \mathrm{~g} / \mathrm{kg}$ alcohol i.p. injection $(P>0.05$; Figure 1f).

\section{No Role in Acute Sedating Effects of Alcohol}

There was no genotype difference in the sedating effects of alcohol between groups of alcohol-naive mice following acute or subchronic alcohol treatment as measured by the LORR (two-way ANOVA, factor: genotype, $P>0.05$; Figure 2a), but a significant tolerance development (factor: test time; duration: $\mathrm{F}_{1,12}=9.97, P=0.0083$; time: $\left.\mathrm{F}_{1,12}=12.19, P=0.0045\right)$.

\section{Absence of Locomotor Activating Effects}

Alcohol-naive mice showed no differences in locomotor activity between genotypes $(P>0.05$; Figure $3 a)$. An acute alcohol injection increased locomotor activity in WT but not $\alpha \mathrm{CaMKII}^{\mathrm{T} 286 \mathrm{~A}}$ or Het mice (Figure 3b). Although twoway ANOVA failed to show significant genotype effects or interactions $(P>0.05)$, preplanned comparisons revealed a significant difference between $\alpha \mathrm{CaMKII}^{\mathrm{T} 286 \mathrm{~A}}$ and WT mice $60 \mathrm{~min}$ after acute alcohol injection (LSD, $P=0.03$ ). Basal behavioral activation levels of $\alpha \mathrm{CaMKII}^{\mathrm{T} 286 \mathrm{~A}}$ but not WT or Het mice increased after subchronic alcohol treatment
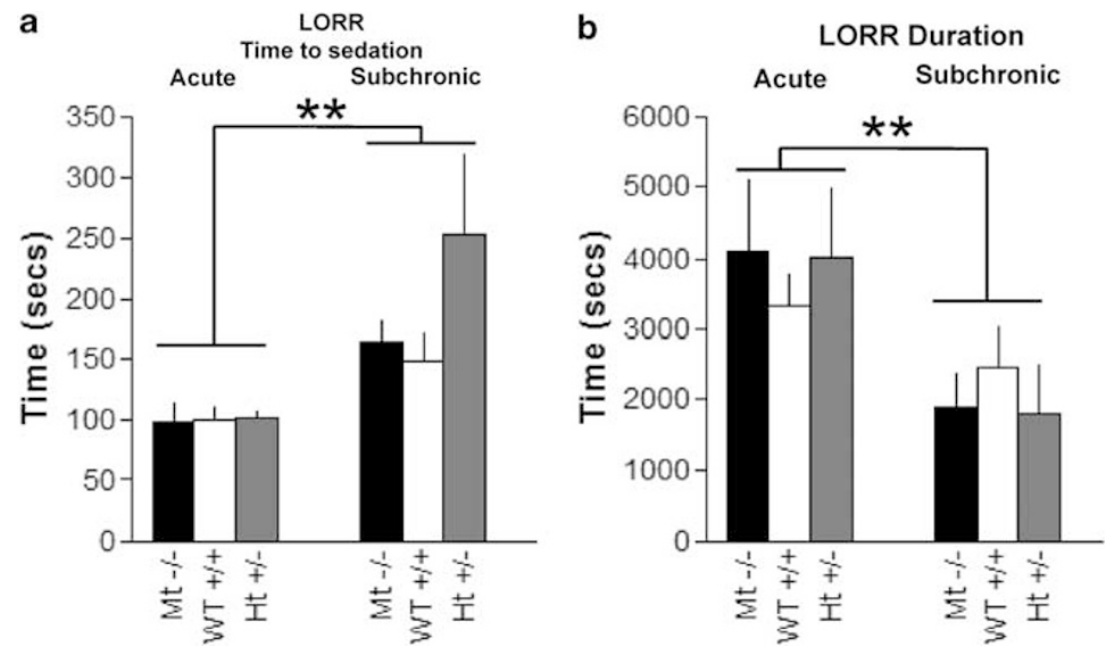

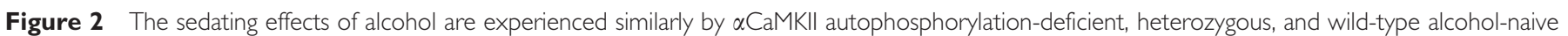

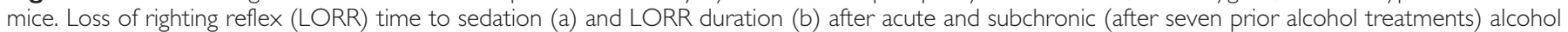

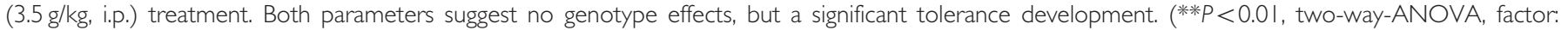
treatment time). 
a

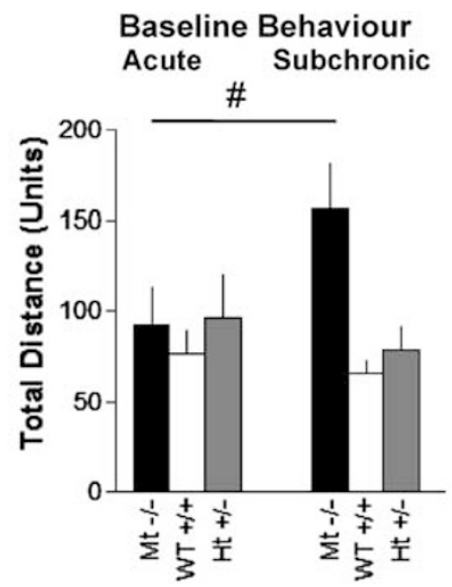

b

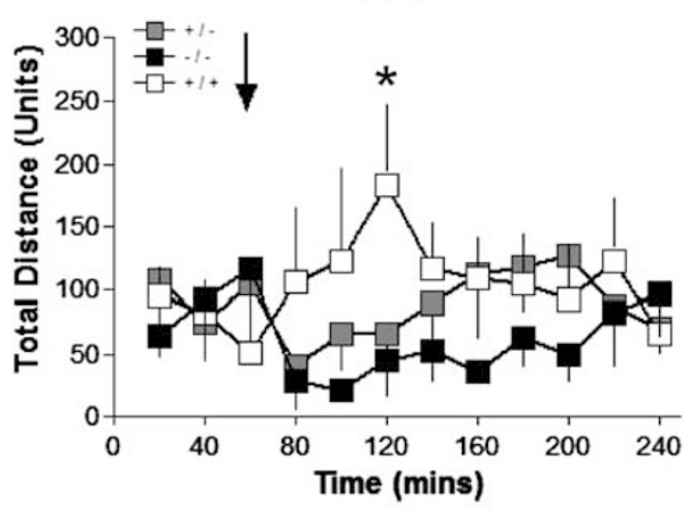

C

Subchronic

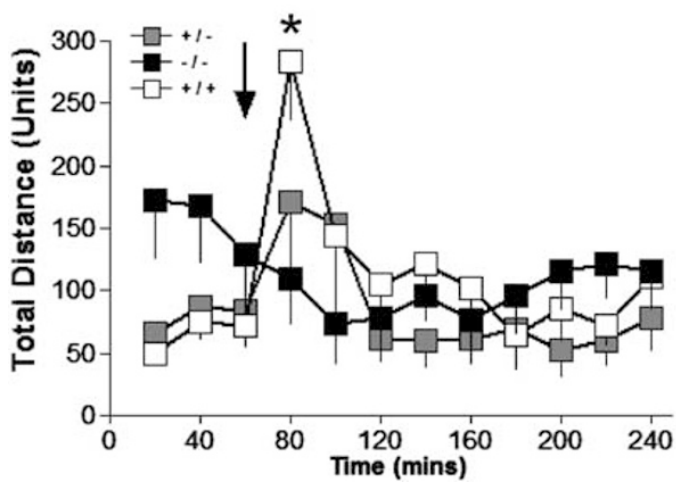

Figure 3 The effects of an alcohol $(2 \mathrm{~g} / \mathrm{kg}$, i.p.) injection on $\alpha \mathrm{CaMKII}$ autophosphorylation-deficient and wild-type mice in a well-habituated ( $>2 \mathrm{~h}$ before baseline) open field. (a) Baseline behavioral activity is not different between genotypes ( $\left.{ }^{P} P<0.05\right)$. Locomotor activity recorded after acute (b) and subchronic (seven) alcohol treatments (c). Arrow indicates time of alcohol injection ( $* P<0.05$ vs MT).

(LSD vs acute, $P<0.05$; Figure $3 \mathrm{a}$ ). Following seven prior daily alcohol treatments, an alcohol injection produced a significant increase in locomotor activity in WT and Het but not $\alpha \mathrm{CaMKII}^{\mathrm{T} 286 \mathrm{~A}}$ mice (Figure $3 \mathrm{c}$; two-way ANOVA; time: $\mathrm{F}_{11,231}=2.97, \quad P=0.001$; interaction: $\mathrm{F}_{22,231}=1.83$, $P=0.02$ ). Preplanned comparisons showed a significant difference between groups at $20 \mathrm{~min}$. (LSD, MT vs WT: $P=0.05)$ after injection. These findings suggest that the locomotor activating effects of alcohol are absent in $\alpha$ CaMKII $^{\text {T286A }}$ mice following both acute and subchronic exposure.

The Acute Dopaminergic Effects of Alcohol in NAcc Are Absent

Mesolimbic DA activation is a crucial mediator of the reinforcing effects of alcohol (Di Chiara and Imperato, 1988; Spanagel, 2009). There were no differences in basal DA levels in the NAcc or PFC between $\alpha \mathrm{CaMKII}^{\mathrm{T} 286 \mathrm{~A}}$ and WT mice $(P>0.05$, Table 1). Acute alcohol administration increased extracellular DA levels in the NAcc of WT mice (Figure 4a; two-way ANOVA, genotype: $\mathrm{F}_{2,26}=4.20$, $P=0.03$; time: $\mathrm{F}_{11,286}=2.21, P=0.01$ ). Preplanned comparisons revealed a significant increase in DA levels in the NAcc in WT mice at $40 \mathrm{~min}$ (LSD vs MT, $P=0.028$ ), $80 \mathrm{~min}$ $(P=0.01), 100 \mathrm{~min}(P=0.01)$, and $120 \mathrm{~min}(P=0.04)$ after injection. This DA increase was absent in $\alpha \mathrm{CaMKII}^{\mathrm{T} 286 \mathrm{~A}}$ and Het mice. DA levels in the PFC of all mice did not change in response to an alcohol challenge $(P>0.05$, Supplementary Figure S1A). After subchronic alcohol exposure, an acute alcohol injection led to an increase in NAcc DA levels in WT mice, which was less pronounced than in naive animals (Figure 4b; two-way ANOVA, $P>0.05$ ). Preplanned comparisons revealed significant differences between WT and $\alpha$ CaMKII $^{\text {T286A }}$ mice only $100 \mathrm{~min}$ (LSD vs MT, $P=0.02$ ) after alcohol administration. The DA response was unchanged in $\alpha \mathrm{CaMKII}^{\mathrm{T} 286 \mathrm{~A}}$ and Het mice, thus reducing response differences between genotype groups. Subchronic DA levels in the PFC were not significantly different between groups $(P>0.05$; Supplementary Figure $S 1 B)$. These data suggest a functional link between $\alpha$ CaMKII autophosphorylation and the DA increase in the NAcc as a crucial marker for the (positive) reinforcing effects of alcohol.

Increased 5-HT Response in the PFC after Acute Alcohol Treatment

Serotonergic mechanisms are well known to orchestrate the behavioral effects of alcohol (McBride, 2010). CaMKII was shown to control 5-HT activity at synaptic level (Liu et al, 2005). There were no differences in basal 5-HT levels in the NAcc or PFC between $\alpha \mathrm{CaMKII}^{\mathrm{T} 286 \mathrm{~A}}$ and WT mice $(P>0.05$, Table 1). After first alcohol treatment, 5-HT in the NAcc was not significantly different between genotypes in this study (Supplementary Figure S1C). In WT and Het animals, there was no effect of alcohol on 5-HT levels in the PFC. However, in $\alpha \mathrm{CaMKII}^{\mathrm{T} 286 \mathrm{~A}}$ mice, alcohol led to a $5-\mathrm{HT}$ increase (Figure 4c; two-way ANOVA, genotype $\times$ time interaction: $\left.\mathrm{F}_{22,319}=2.22, P=0.001\right)$. Preplanned comparisons showed a significant differences between $\alpha \mathrm{CaMKII}^{\mathrm{T} 286 \mathrm{~A}}$ and WT $20 \mathrm{~min}(\mathrm{LSD}, P=0.008)$ and $40 \mathrm{~min}(P=0.001)$ after alcohol administration. After subchronic alcohol treatments, an acute alcohol challenge did not alter serotonergic responses in the NAcc $(P>0.05$; Supplementary Figure S1D). In the PFC, there was no effect of alcohol on 5-HT levels in WT or Het animals, but an increase in $\alpha \mathrm{CaMKII}^{\mathrm{T} 286 \mathrm{~A}}$ mice (Figure 4d; two-way ANOVA; $P>0.05$ ). Preplanned comparisons revealed significant differences between $\alpha$ CaMKII $^{\text {T286A A }}$ and WT $120 \mathrm{~min}$ (LSD, $P=0.05$ ) and $160 \mathrm{~min}(P=0.02)$ after alcohol injection. These findings 
Table I Baseline Monoamine Levels before Acute Treatment and after Subchronic Alcohol Exposure

\begin{tabular}{|c|c|c|c|c|c|}
\hline Brain area & Time point & Transmitter & WT & Het & MT \\
\hline \multirow[t]{2}{*}{ NAcc } & Acute & DA & $2.06( \pm 0.5 I)$ & $1.59( \pm 0.21)$ & $1.59( \pm 0.21)^{\$}$ \\
\hline & & $5-\mathrm{HT}$ & $2.65( \pm 0.63)$ & $10.16( \pm 2.42)^{*}$ & $1.14( \pm 0.17)^{\#}$ \\
\hline \multirow[t]{2}{*}{ PFC } & Acute & DA & $2.08( \pm 0.65)$ & $1.23( \pm 0.27)^{\$}$ & $1.08( \pm 0.16)$ \\
\hline & & $5-\mathrm{HT}$ & $1.37( \pm 0.31)$ & $6.73( \pm 1.19)^{*}$ & $1.12( \pm 0.19)^{\#}$ \\
\hline NAcc & Subchronic & DA & $1.93( \pm 0.39)$ & $2.48( \pm 0.73)$ & $3.12( \pm 0.55)$ \\
\hline & & $5-\mathrm{HT}$ & $3.11( \pm 0.93)$ & $11.95( \pm 3.07)^{*}$ & $0.85( \pm 0.14)^{\#}$ \\
\hline
\end{tabular}

Abbreviations: DA, dopamine; 5-HT, serotonin; NAcc; nucleus accumbens; PFC, prefrontal cortex.

${ }^{*} P<0.05$ vs WT.

${ }^{\#} P<0.05$ vs Het.

$\$ p<0.05$ vs subchronic.

Data show neurotransmitter levels expressed as pg per $30 \mu \mathrm{l}( \pm \mathrm{SEM})$ in the NAcc and PFC.
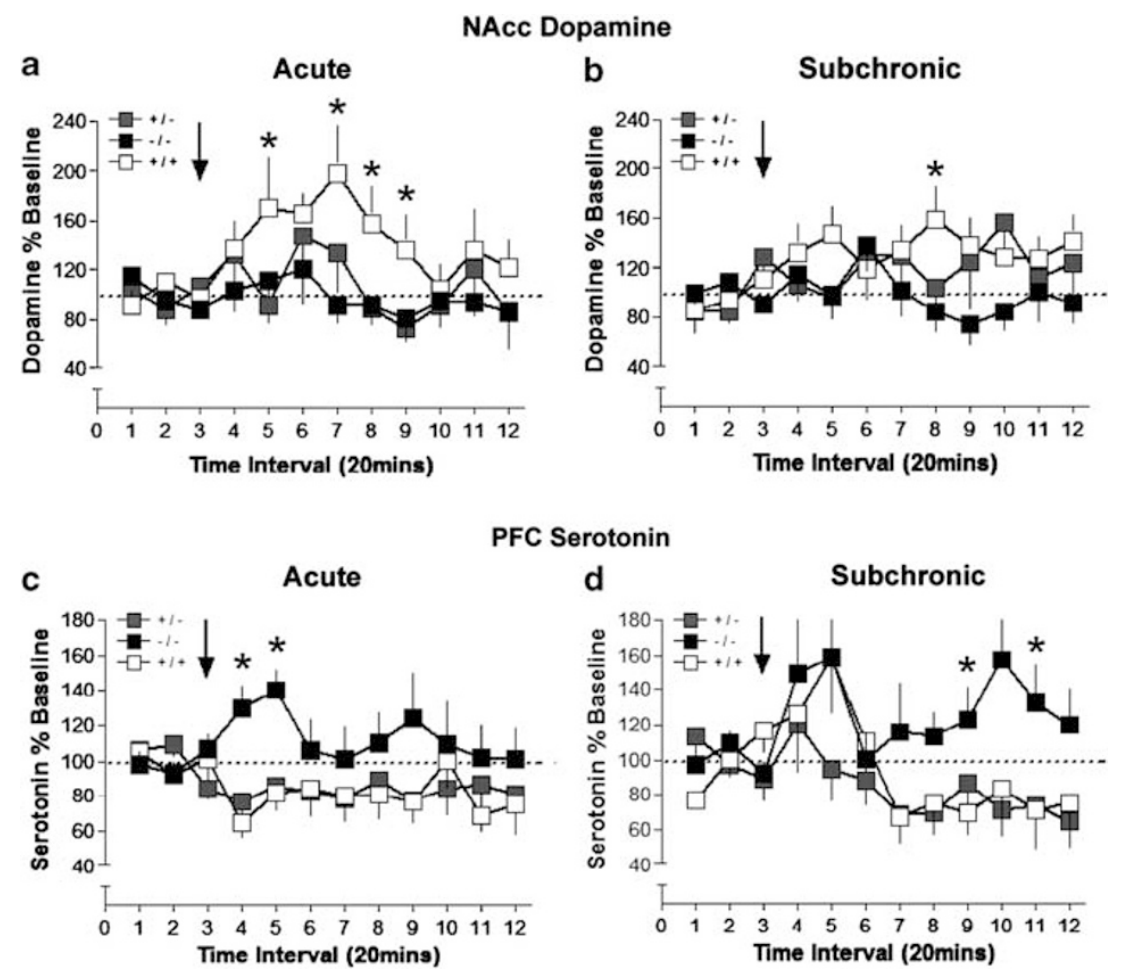

Figure 4 Acute and subchronic alcohol effects on monoamine activity represented as percent of baseline (mean \pm SEM). (a) Extracellular dopamine (DA) levels in the nucleus accumbens (NAcc) after acute alcohol treatment. (b) Effects of subchronic alcohol treatment on dopamine levels in the NAcc. (c) Extracellular serotonin (5-HT) levels in the prefrontal cortex (PFC) after acute alcohol treatment. (d) Effects of subchronic alcohol treatments on PFC 5-HT levels. Arrows indicate time of alcohol injection (preplanned comparison between groups at each time point: $* P<0.05$, MT vs WT).

suggest an inhibitory effect of $\alpha$ CaMKII autophosphorylation on 5-HT responses to alcohol in the PFC.

\section{Enhanced c-Fos Activation in the Rostral But Not Caudal VTA after Alcohol}

In order to determine the origin of altered DA responses to alcohol, we further investigated the effects of acute and subchronic alcohol administration on c-Fos activation in the rostral and caudal VTA (Figure 5). $\alpha$ CaMKII ${ }^{\mathrm{T} 286 \mathrm{~A}}$ mice showed an increased c-Fos expression in the rostral part of the VTA after both acute $\left(\mathrm{F}_{1,10}=6.32, P<0.05\right)$ and subchronic $\left(F_{1,9}=20.7, P<0.01\right)$ alcohol treatment. There was no significant difference between $\alpha \mathrm{CaMKII}^{\mathrm{T} 286 \mathrm{~A}}$ and WT animals in c-Fos expression in the caudal part of the VTA $(P>0.05)$. The rostral VTA contains predominantly 
caudal VTA

rostral VTA
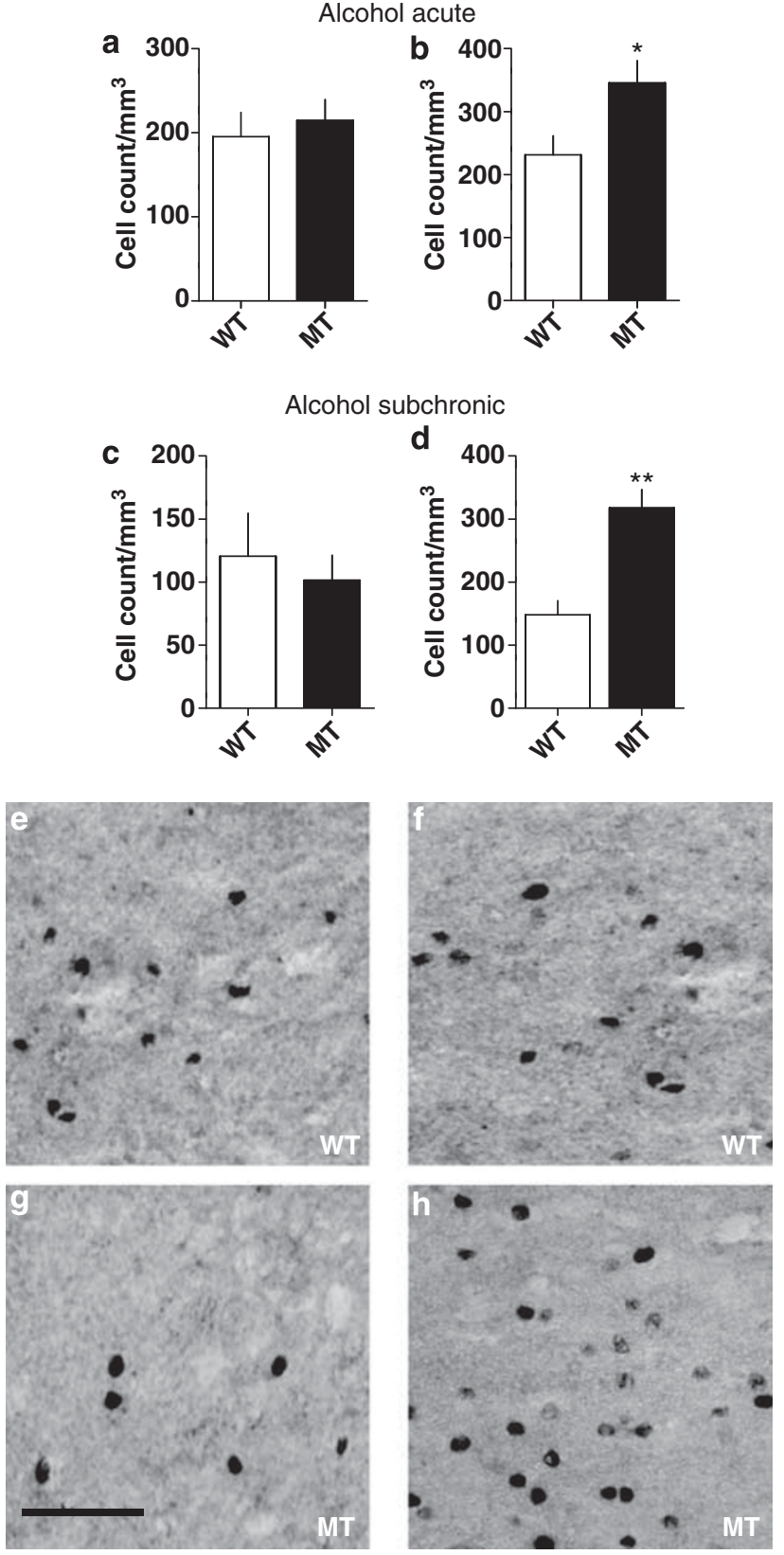

Figure 5 aCaMKII autophosphorylation-deficient mice show an increased c-Fos expression in the rostral, but not caudal, ventral tegmental area (VTA) after both acute and subchronic alcohol treatment. c-Fos labeling of the caudal ( $a, c, e, g, P>0.05)$ and rostral VTA (b, d, f, h) after acute or 7 days of subchronic alcohol $(2 \mathrm{~g} / \mathrm{kg}$, i.p.) treatment. C-Fos was determined $70 \mathrm{~min}$ after last alcohol injection (ANOVA, $* P<0.05$, $\left.{ }^{*} * P<0.0 \mathrm{I}\right)$. (e-h) c-Fos-labeled cells of the VTA after single acute alcohol treatment $($ bar $=100 \mu \mathrm{m})$.

GABAergic neurons (Olson and Nestler, 2007). In order to estimate the relative number of GABAergic cells within the VTA that show c-Fos activation after alcohol treatment, we performed GAD67/c-Fos double labeling in representative animals. We found that 68 and $40 \%$ of the c-Fos-activated cells were also GAD67 positive in the rostral and caudal VTA, respectively (Supplementary Figure S2).

\section{CAMK2A Gene SNPs Predict Alcohol Dependence in Male Humans}

Although there is no naturally occurring gene mutation affecting the autophosphorylation site in humans, there are SNPs in the CAMK2A gene that may affect general activity and indirectly autophosphorylation. The genotype distribution of all investigated SNPs was in accordance with HardyWeinberg expectations $(P>0.1)$. Of the 23 SNPs typed from the CAMK2A gene, 7 were found to be significantly associated with alcohol dependence: $\operatorname{rs3822607}(P=0.015$, $\mathrm{FDR}=0.0496), \quad \operatorname{rs} 3776825 \quad(P=0.012, \quad \mathrm{FDR}=0.0460)$, rs7711562 $(P=0.0034, \mathrm{FDR}=0.0391), \operatorname{rs} 3756577(P=0.012$, $\mathrm{FDR}=0.0460), \quad \mathrm{rs} 10463293 \quad(P=0.0028, \quad \mathrm{FDR}=0.0391)$, rs4958445 $(P=0.0091, \quad \mathrm{FDR}=0.0460), \quad$ and $\quad \mathrm{rs} 4958902$ $(P=0.012, \mathrm{FDR}=0.0460$; Table 2$)$. Haplotype-based analysis of human genotype data did not reveal additional insights (Supplementary Table S1). These findings may suggest a functional effect of genetic mutations in the CAMK2A gene on alcohol consumption in humans also.

\section{DISCUSSION}

Here we report that $\alpha$ CaMKII ${ }^{\mathrm{T} 286 \mathrm{~A}}$ mice prefer alcohol significantly less than WT animals-especially at higher percent alcohol solutions. This effect was persistent until animals were withdrawn twice from alcohol. Taste sensitivity remains largely unaffected, although $\alpha$ CaMKII autophosphorylation deficiency may slightly reduce the incentive properties of a sucrose solution. Alcohol bioavailability was found to be comparable across genotypes. Whereas the locomotor activating effects of a low dose of alcohol were absent in $\alpha$ CaMKII ${ }^{\mathrm{T} 286 \mathrm{~A}}$ mice after acute and subchronic exposure, sedating effects of a high dose were preserved. The lack of $\alpha$ CaMKII autophosphorylation did not change DA or 5-HT basal activity, but coincided with a lack of the acute DA response to alcohol in the NAcc. Interestingly, it provoked a 5-HT increase in the PFC. Both effects suggest a strong link between $\alpha$ CaMKII autophosphorylation and monoaminergic responses to alcohol. An analysis of the cellular activation of the VTA, as an origin of the mesolimbic DA projections, revealed an enhanced activation after acute and subchronic alcohol in the rostral but not caudal region in the $\alpha \mathrm{CaMKII}^{\mathrm{T} 286 \mathrm{~A}}$ mice, which appeared to be driven predominantly by GABAergic neurons. Animal data suggest that $\alpha$ CaMKII autophosphorylation may control the speed at which alcohol preference is established, but not the capacity to consume alcohol. A comparative approach, using a human sample, confirmed the link between genetic mechanisms controlling $\alpha$ CaMKII activity and alcohol consumption by means of an association between naturally occurring SNPs and alcohol dependence.

The DA system is critical for the establishment of the acute reinforcing effects of alcohol (Koob et al, 1998; McBride et al, 1999). We have shown that an acute alcohol challenge induces a DA increase in the NAcc of WT mice. This response was entirely absent in Het and $\alpha \mathrm{CaMKII}^{\mathrm{T} 286 \mathrm{~A}}$ mice. This finding suggests that $\alpha \mathrm{CaMKII}$ autophosphorylation is required for the alcohol-induced DA increase in the NAcc. The lack of a DA response in the $\alpha \mathrm{CaMKII}^{\mathrm{T} 286 \mathrm{~A}}$ mice is therefore a likely mechanism to explain the initially 
Table 2 Association of CAMK2A Single-Nucleotide Polymorphisms with Alcohol Dependence in a Sample of I 333 Male DSM-IV AlcoholDependent Patients and 939 Male Controls

\begin{tabular}{|c|c|c|c|c|c|c|c|c|c|}
\hline Marker & Chromosomal position & Minor allele & Major allele & $\mathbf{F} A^{\mathrm{a}}$ & F_U $\mathbf{U}^{\mathrm{b}}$ & $P$-Value & Odds ratio ${ }^{c}$ & $95 \% \mathrm{Cl}$ & FDR \\
\hline rs6869490 & 149600448 & $\mathrm{~T}$ & C & 0.05 & 0.06 & $3.5 E-01$ & 0.88 & $(0.68-1.15)$ & 0.4956 \\
\hline rs2241694 & 149602608 & A & G & 0.06 & 0.07 & $9.4 \mathrm{E}-02$ & 0.82 & $(0.65-1.04)$ & 0.2164 \\
\hline rs6885505 & I 49608779 & G & $\mathrm{T}$ & 0.36 & 0.38 & $1.6 \mathrm{E}-0 \mid$ & 0.92 & $(0.81-1.04)$ & 0.3137 \\
\hline rs2053053 & 149609393 & $\mathrm{~T}$ & C & 0.36 & 0.38 & $1.8 \mathrm{E}-0 \mid$ & 0.92 & $(0.81-1.04)$ & 0.3137 \\
\hline rs 171 I 1079 & 149615774 & $A$ & G & 0.11 & 0.11 & $6.3 \mathrm{E}-01$ & 1.05 & $(0.87-1.27)$ & 0.6907 \\
\hline rs6869|80 & 149616620 & $T$ & C & 0.01 & 0.01 & $7.8 \mathrm{E}-01$ & 0.93 & $(0.55-1.57)$ & 0.7847 \\
\hline rs3797617 & 149619499 & $\mathrm{~T}$ & C & 0.16 & 0.17 & $1.7 \mathrm{E}-0 \mid$ & 0.89 & $(0.76-1.05)$ & 0.3137 \\
\hline rs3776825* & |4962067| & $\mathrm{T}$ & $C$ & 0.28 & 0.32 & $1.2 \mathrm{E}-02$ & 0.85 & $(0.74-0.96)$ & 0.0460 \\
\hline rs4958456 & 149623365 & $A$ & G & 0.13 & 0.15 & $4.9 E-02$ & 0.84 & $(0.7|-| .00)$ & 0.1252 \\
\hline rs 10463293* & 149636073 & G & $\mathrm{T}$ & 0.43 & 0.47 & $2.8 \mathrm{E}-03$ & 0.83 & $(0.74-0.94)$ & 0.0391 \\
\hline rs4958445* & 149638360 & $\mathrm{~T}$ & $C$ & 0.26 & 0.30 & $9.1 E-03$ & 0.84 & $(0.74-0.96)$ & 0.0460 \\
\hline rs4958902* & I 49648780 & $\mathrm{~T}$ & G & 0.15 & 0.18 & $1.2 \mathrm{E}-02$ & 0.81 & $(0.69-0.95)$ & 0.0460 \\
\hline rs874083 & 149650925 & A & G & 0.18 & 0.18 & $6 .|E-0|$ & 1.04 & $(0.89-1.21)$ & 0.6907 \\
\hline rs| 897559 & 149656212 & G & A & 0.11 & 0.11 & $7 .|\mathrm{E}-0| \mathrm{I}$ & 0.97 & $(0.80-1.16)$ & 0.7474 \\
\hline rsI05I5639 & 149656426 & $\mathrm{~T}$ & $C$ & 0.20 & 0.19 & $2.4 \mathrm{E}-0 \mathrm{I}$ & 1.10 & $(0.94-1.27)$ & 0.3920 \\
\hline rs| 432833 & $|4966| 153$ & G & A & 0.21 & 0.22 & $3.5 \mathrm{E}-0 \mathrm{O}$ & 0.93 & $(0.8|-| .08)$ & 0.4956 \\
\hline rs919740 & 149665849 & C & $\mathrm{T}$ & 0.21 & 0.22 & $4.9 E-01$ & 0.95 & $(0.82-1.10)$ & 0.5957 \\
\hline
\end{tabular}

${ }^{*} P<0.05$.

a Minor allele frequency in patients.

${ }^{b}$ Minor allele frequency in controls.

${ }^{\mathrm{c}}$ Refers to minor allele.

reduced alcohol preference in a free access condition. Activation of the dopaminergic neurons in the VTA is believed to be critically involved in the development of addiction (Robbins and Everitt, 1996; Koob et al, 1998). Projections from the VTA extend to regions implicated in the rewarding potential of drugs of abuse, including the NAcc (Van Bockstaele and Pickel, 1995; Olson et al, 2005) and the PFC (Carr and Sesack, 2000). An activation of the caudal VTA dopaminergic neurons, which is mediated by a reduced GABAergic signaling (Theile et al, 2011), is one of the cellular bases for alcohol reinforcement (Brodie et al, 1999; Xiao et al, 2009). Several studies have demonstrated that as the GABAergic activity in rostral VTA increases, the dopaminergic activity decreases, resulting in a diminished experience of reward and reinforcement (Ikemoto et al, 1997; Ding et al, 2009). We observed an increased rostral VTA c-Fos activation after alcohol in the $\alpha$ CaMKII ${ }^{\mathrm{T} 286 \mathrm{~A}}$ mice, which is in line with the observation of reduced alcohol consumption and the lack of locomotor activating effects. The majority of the c-Fos-activated cells appeared to be GABAergic. Activation of GABAergic neurons in the VTA may induce an aversive state (Tan et al, 2012) and disrupt reward consumption. This may occur by inhibiting DA neurons and DA release, or via ascending GABAergic projections (van Zessen et al, 2012). We did not find an altered activation after alcohol in the caudal VTA of $\alpha$ CaMKII $^{\mathrm{T} 286 \mathrm{~A}}$ mice. Together, this may suggest that the lack of an alcohol-induced DA increase in the NAcc was not mediated by altered responsiveness of DA neurons in the VTA, but possibly by direct VTA GABAergic inputs to the NAcc (van Zessen et al, 2012).

Alcohol administration increases 5-HT activity in the ventral hippocampus (McBride et al, 1999; Thielen et al, 2002). In our study, alcohol did not affect 5-HT activity in the NAcc or PFC in WT or Het animals. In $\alpha \mathrm{CaMKII}^{\mathrm{T} 286 \mathrm{~A}}$ animals, however, alcohol induced a significant 5-HT increase in the PFC. Interestingly, Het mice showed neither a strong DA nor 5-HT response, suggesting an absence of the reinforcing effects of alcohol. This is in line with Het behavior in that they drop back to low consumption after two withdrawals (Figure 1c). Deficiencies in brain 5-HT levels and turnover have previously been associated with high alcohol drinking (Murphy et al, 1982; Virkkunen and Linnoila, 1997; Smith et al, 2008). Conversely, artificially induced increases in extracellular 5-HT levels can reduce alcohol drinking (Boyce-Rustay et al, 2006). The alcoholinduced 5-HT increases in the PFC of $\alpha$ CaMKII ${ }^{\mathrm{T} 286 \mathrm{~A}}$ mice may, therefore, contribute to the reduced alcohol drinking 


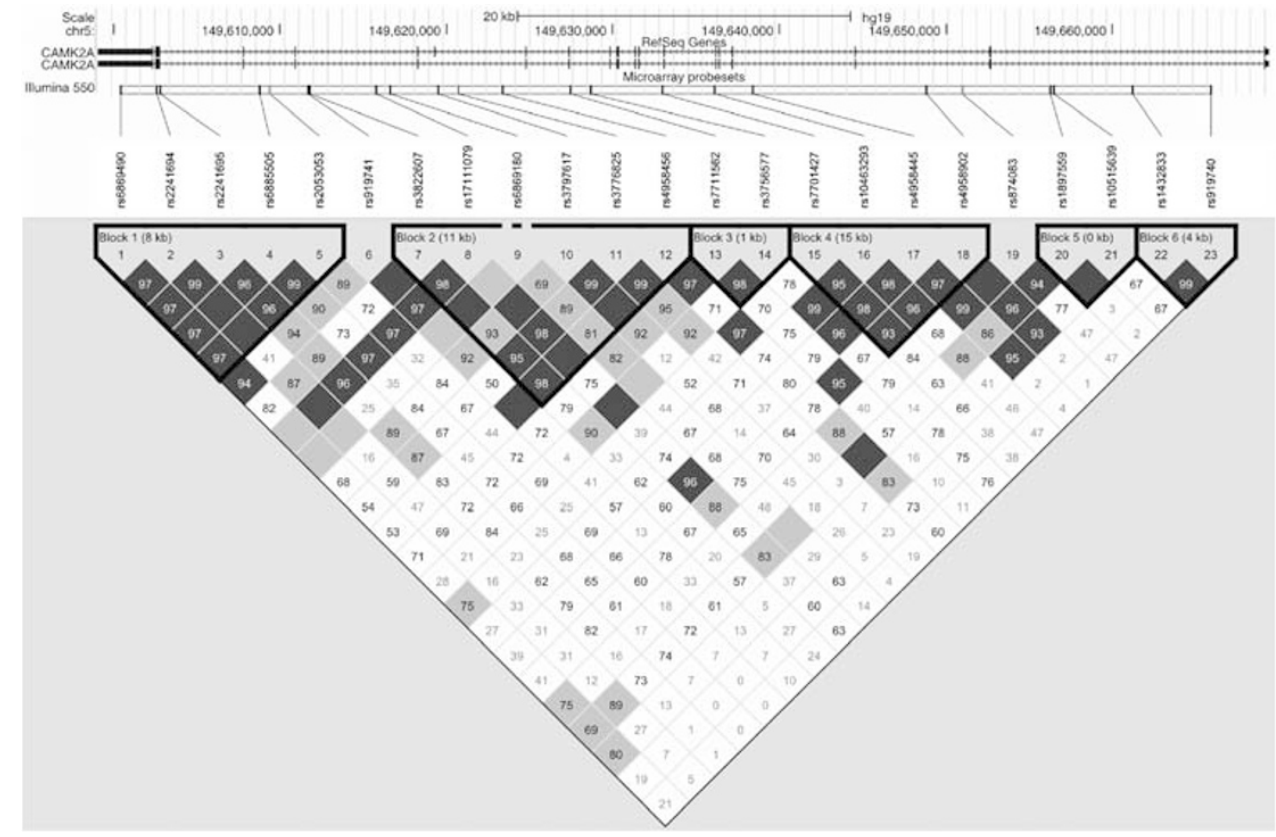

Figure 6 Exon-intron structure of the CAMK2A gene (isoforms I and 2), according to UCSC genome browser (https://genome.ucsc.edu). Included are chromosomal position and haplotype block structure of assessed markers. Haplotype blocks are framed in black. Numbers in gray-shaded squares denote pairwise D' between single markers. Gray scheme encodes LD between markers using D' confidence intervals (uninformative: gray; strong evidence for LD: dark gray; strong evidence for recombination: white).

seen in these mice. There is a strong link between CaMKII and serotonergic function in the brain. CaMKII is required for the phosphorylation and activation of tryptophan hydroxylase (TPH), the rate-limiting enzyme in the biosynthesis of 5-HT (Kuhn et al, 1982, 2007; Ehret et al, 1989). The administration of the CaMKII inhibitor, KN-62, has been shown to increase the firing rate of 5-HT neurons (Liu et al, 2005). This finding is in line with the present data, whereby a reduced CaMKII function may increase 5-HT neuronal firing and terminal 5-HT release, which inhibits alcohol consumption. As the 5-HT response is still observed after subchronic administration in the $\alpha$ CaMKII ${ }^{\mathrm{T} 286 \mathrm{~A}}$ mice, one may speculate that the ADE-induced increase in alcohol drinking is mediated by nonmonoaminergic mechanisms (Spanagel, 2009).

At a low dose $(2 \mathrm{~g} / \mathrm{kg}$, i.p. $)$, alcohol has locomotor stimulant effects upon acute and subchronic treatment in the WT animals. This effect was absent in $\alpha$ CaMKII ${ }^{\mathrm{T} 286 \mathrm{~A}}$ and Het mice. These findings may suggest that $\alpha$ CaMKII autophosphorylation is required for the locomotor stimulant effects of a low dose of alcohol. Subchronic treatment with alcohol increased baseline locomotor activity in $\alpha \mathrm{CaMKII}{ }^{\mathrm{T} 286 \mathrm{~A}}$ but not WT or Het mice. This may have been caused by a parallel increase in basal DA levels in the NAcc in $\alpha$ CaMKII ${ }^{\mathrm{t} 286 \mathrm{~A}}$ but not WT or Het mice (Gong et al, 1999).

A recent study showed that alcohol-induced LORR is controlled by $\alpha$ CaMKII-bearing neurons in the dorsal striatum (Kim et al, 2012). Here we report that the sedative properties of a high dose of alcohol were not affected by a deficit in $\alpha$ CaMKII autophosphorylation. This may suggest that alcohol LORR may depend on $\alpha$ CaMKII but not its autophosphorylation.
In agreement with the animal data, we found several associations of polymorphisms in the human CAMK2A gene with alcohol dependence. Of the 23 SNPs typed from the CAMK2A gene, 7 were found to be significant, one of which (rs10463293) has previously been associated with working memory performance (Easton et al, 2012) suggesting that CAMK2A may play a role in both. The nonsynonymous autophosphorylation SNP described in the animal literature (Giese et al, 1989) is a coding SNP located in exon 11 of the human CAMK2A gene (rs35495165). One of the significantly associated SNPs (rs3756577) in this study, located in intron 11 , immediately flanks the functional polymorphism of interest and may therefore be acting as a tagging SNP for the autophosphorylation SNP, which was not typed in this sample.

Altogether, the present study suggests that $\alpha$ CaMKII autophosphorylation might play an important role in the establishment of alcohol drinking behavior in mice and humans. A lack of $\alpha$ CaMKII autophosphorylation delays the establishment of this behavior significantly. $\alpha$ CaMKII autophosphorylation is required to express a DA increase in the NAcc as a functional marker for the positive reinforcing effects of alcohol. Its lack leads to a DA-5-HT response imbalance in the mesocorticolimbic system.

\section{ACKNOWLEDGEMENTS}

We thank Mr Jörg Distler for his expert technical assistance. This work was supported by funds of the Institute of Psychiatry, King's College London, and by FriedrichAlexander-University of Erlangen-Nuremberg. ACE is a recipient of a studentship from the Medical Research 
Council, UK. GS is receiving funding from the European Union-funded FP6 Integrated Project IMAGEN (Reinforcement-related behavior in normal brain function and psychopathology; LSHM-CT- 2007-037286) and FP7 project ADAMS (Genomic variations underlying common neuropsychiatric diseases and disease-related cognitive traits in different human populations; 242257), as well as the United Kingdom National Institute for Health Research (NIHR) Biomedical Research Centre Mental Health and the Medical Research Council Programme Grant 'Developmental pathways into adolescent substance abuse' (93558).

\section{DISCLOSURE}

The authors declare no conflict of interest. P Lewczuk is a consultant of Innogenetics, Ghent, Belgium.

\section{REFERENCES}

Anderson SM, Famous KR, Sadri-Vakili G, Kumaresan V, Schmidt HD, Bass CE et al (2008). CaMKII: a biochemical bridge linking accumbens dopamine and glutamate systems in cocaine seeking. Nat Neurosci 11: 344-353.

Benjamini Y, Hochberg Y (1995). Controlling the false discovery rate: a practical and powerful approach to multiple testing. J Royal Stat Soc Series B 57: 289-300.

Boyce-Rustay JM, Wiedholz LM, Millstein RA, Carroll J, Murphy DL, Daws DC et al (2006). Ethanol-related behaviors in serotonin transporter knockout mice. Alcohol Clin Exp Res 30: 1957-1965.

Brodie MS, Pesold C, Appel SB (1999). Ethanol directly excites dopaminergic ventral tegmental area reward neurons. Alcohol Clin Exp Res 23: 1848-1852.

Carr DB, Sesack SR (2000). GABA-containing neurons in the rat ventral tegmental area project to the prefrontal cortex. Synapse 38: 114-123.

Choe ES, Wang JQ (2002). CaMKII regulates amphetamineinduced ERK1/2 phosphorylation in striatal neurons. Neuroreport 13: 1013-1016.

Colbran RJ, Brown AM (2004). Calcium/calmodulin-dependent protein kinase II and synaptic plasticity. Curr Opin Neurobiol 14: 318-327.

Di Chiara G, Imperato A (1988). Drugs abused by humans preferentially increase synaptic dopamine concentrations in the mesolimbic system of freely moving rats. Proc Natl Acad Sci USA 85: 5274-5278.

Ding ZM, Liu W, Engleman EA, Rodd ZA, McBride WJ (2009). Differential effects of dopamine D2 and GABA(A) receptor antagonists on dopamine neurons between the anterior and posterior ventral tegmental area of female Wistar rats. Pharmacol Biochem Behav 92: 404-412.

Easton AC, Lourdusamy A, Loth E, Toro R, Giese KP, Kornhuber J et al (2012). CAMK2A polymorphisms predict working memory performance in humans. Mol Psychiatry doi:10.1038/ mp.2012.114.

Easton AC, Lucchesi W, Schumann G, Giese KP, Müller CP, Fernandes C (2011). $\alpha$ CaMKII autophosphorylation controls exploratory activity to threatening novel stimuli. Neuropharmacology 61: 1424-1431.

Ehret M, Cash CD, Hamon M, Maitre M (1989). Formal demonstration of the phosphorylation of rat brain tryptophan hydroxylase by $\mathrm{Ca} 2+/$ calmodulin-dependent protein kinase. J Neurochem 52: 1886-1891.

Elgersma Y, Sweatt JD, Giese KP (2004). Mouse genetic approaches to investigating calcium/calmodulin-dependent protein kinase II function in plasticity and cognition. J Neurosci 24: 8410-8415.

Frank J, Cichon S, Treutlein J, Ridinger M, Mattheisen M, Hoffmann P et al (2012). Genome-wide significant association between alcohol dependence and a variant in the ADH gene cluster. Addict Biol 17: 171-180.

Franklin KBJ, Paxinos G (1997). The Mouse Brain in Stereotaxic Coordinates, 2nd edn. Academic Press: San Diego.

Gabriel SB, Schaffner SF, Nguyen H, Moore JM, Roy J, Blumenstiel B et al (2002). The structure of haplotype blocks in the human genome. Science 296: 2225-2229.

Garic A, Flentke GR, Amberger E, Hernandez M, Smith SM (2011). CaMKII activation is a novel effector of alcohol's neurotoxicity in neural crest stem/progenitor cells. J Neurochem 118: 646-657.

Giese KP, Fedorov NB, Filipkowski RK, Silva AJ (1989). Autophosphorylation at Thr286 of the alpha calcium-calmodulin kinase II in LTP and learning. Science 279: 870-873.

Gong W, Neill DB, Lynn M, Justice JB Jr (1999). Dopamine D1/D2 agonists injected into nucleus accumbens and ventral pallidum differentially affect locomotor activity depending on site. Neuroscience 93: 1349-1358.

Ikemoto S, Kohl RR, McBride WJ (1997). GABA(A) receptor blockade in the anterior ventral tegmental area increases extracellular levels of dopamine in the nucleus accumbens of rats. J Neurochem 69: 137-143.

Irvine EE, Vernon J, Giese KP (2005). AlphaCaMKII autophosphorylation contributes to rapid learning but is not necessary for memory. Nat Neurosci 8: 411-412.

Irvine EE, von Hertzen LS, Plattner F, Giese KP (2006). alphaCaMKII autophosphorylation: a fast track to memory. Trends Neurosci 29: 459-465.

Kelley AE (2004). Memory and addiction: shared neural circuitry and molecular mechanisms. Neuron 44: 161-179.

Kim KS, Kim H, Park SK, Han PL (2012). The dorsal striatum expressing adenylyl cyclase-5 controls behavioral sensitivity of the righting reflex to high-dose ethanol. Brain Res 1489: 27-36.

Koob GF, Sanna PP, Bloom FE (1998). Neuroscience of addiction. Neuron 21: 467-476.

Kourrich S, Klug JR, Mayford M, Thomas MJ (2012). AMPARindependent effect of striatal alphaCaMKII promotes the sensitization of cocaine reward. J Neurosci 32: 6578-6586.

Kuhn DM, Lovenberg W (1982). Role of calmodulin in the activation of tryptophan hydroxylase. Fed Proc 41: 2258-2264.

Kuhn DM, Sakowski SA, Geddes TJ, Wilkerson C, Haycock JW (2007). Phosphorylation and activation of tryptophan hydroxylase 2: identification of serine-19 as the substrate site for calcium, calmodulin-dependent protein kinase II. J Neurochem 103: $1567-1573$.

Lamsa K, Irvine EE, Giese KP, Kullmann DM (2007). NMDA receptor-dependent long-term potentiation in mouse hippocampal interneurons shows a unique dependence on $\mathrm{Ca}(2+)$ / calmodulin-dependent kinases. J Physiol 584: 885-894.

Lee HY, Yang BC, Lee ES, Chung JI, Koh PO, Park MS et al (2011). Modulation by the GABA(B) receptor siRNA of ethanolmediated PKA-alpha, CaMKII, and p-CREB intracellular signaling in prenatal rat hippocampal neurons. Anat Cell Biol 44: 210-217.

Lenz B, Müller CP, Stoessel C, Sperling W, Biermann T, Hillemacher $\mathrm{T}$ et al (2012). Sex hormone activity in alcohol addiction: integrating organizational and activational effects. Prog Neurobiol 96: 136-163.

Li CY, Mao X, Wei L (2008). Genes and (common) pathways underlying drug addiction. PLoS Comput Biol 4: e2.

Licata SC, Pierce RC (2003). The roles of calcium/calmodulindependent and Ras/mitogen-activated protein kinases in the development of psychostimulant-induced behavioral sensitization. J Neurochem 85: 14-22.

Licata SC, Schmidt HD, Pierce RC (2004). Suppressing calcium/ calmodulin-dependent protein kinase II activity in the ventral tegmental area enhances the acute behavioural response to 
cocaine but attenuates the initiation of cocaine-induced behavioural sensitization in rats. Eur J Neurosci 19: 405-414.

Liu J, Suncion-Chin M, Liu P, Dopico AM (2006). CaM kinase II phosphorylation of slo Thr107 regulates activity and ethanol responses of BK channels. Nat Neurosci 9: 41-49.

Liu RJ, Lambe EK, Aghajanian GK (2005). Somatodendritic autoreceptor regulation of serotonergic neurons: dependence on L-tryptophan and tryptophan hydroxylase-activating kinases. Eur J Neurosci 21: 945-958.

Mahadev K, Chetty CS, Vemuri MC (2001). Effect of prenatal and postnatal ethanol exposure on $\mathrm{Ca} 2+/$ calmodulin-dependent protein kinase II in rat cerebral cortex. Alcohol 23: 183-188.

McBride WJ, Murphy JM, Ikemoto S (1999). Localization of brain reinforcement mechanisms: intracranial self-administration and intracranial place-conditioning studies. Behav Brain Res 101: 129-152.

McBride WJ, Schultz JA, Kimpel MW, McClintick JN, Wang M, You J et al (2009). Differential effects of ethanol in the nucleus accumbens shell of alcohol-preferring (P), alcohol-non-preferring (NP) and Wistar rats: a proteomics study. Pharmacol Biochem Behav 92: 304-313.

McBride WJ (2010). Role of serotonin in brain reward and regulation of alcohol drinking behaviour. In: Müller CP, Jacobs BJ (eds) Handbook of the Behavioral Neurobiology of Serotonin. Academic Press: London. pp 399-414.

Müller CP, Schumann G (2011). Drugs as instruments: a new framework for non-addictive psychoactive drug use. Behav Brain Sci 34: 293-347.

Müller CP, De Souza Silva MA, Huston JP (2007). Double dissociating effects of sensory stimulation and cocaine on serotonin activity in the occipital and temporal cortices. Neuropharmacology 52: 854-862.

Murphy JM, McBride WJ, Lumeng L, Li TK (1982). Regional brain levels of monoamines in alcohol-preferring and -nonpreferring lines of rats. Pharmacol Biochem Behav 16: 145-149.

Nestler EJ (2002). Common molecular and cellular substrates of addiction and memory. Neurobiol Learn Mem 78: 637-647.

Olson VG, Nestler EJ (2007). Topographical organization of GABAergic neurons within the ventral tegmental area of the rat. Synapse 61: 87-95.

Olson VG, Zabetian CP, Bolanos CA, Edwards S, Barrot M, Eisch $\mathrm{AJ}$ et al (2005). Regulation of drug reward by cAMP response element-binding protein: evidence for two functionally distinct subregions of the ventral tegmental area. J Neurosci 25: 5553-5562.

Pierce RC, Quick EA, Reeder DC, Morgan ZR, Kalivas PW (1998). Calcium-mediated second messengers modulate the expression of behavioral sensitization to cocaine. J Pharmacol Exp Ther 286: 1171-1176.

Pum M, Carey RJ, Huston JP, Müller CP (2007). Dissociating effects of cocaine and d-amphetamine on dopamine and serotonin in the perirhinal, entorhinal, and prefrontal cortex of freely moving rats. Psychopharmacology 193: 375-390.

Robbins TW, Everitt BJ (1996). Neurobehavioural mechanisms of reward and motivation. Curr Opin Neurobiol 6: 228-236.

Sakurai S, Yu L, Tan SE (2007). Roles of hippocampal N-methyl-Daspartate receptors and calcium/calmodulin-dependent protein kinase II in amphetamine-produced conditioned place preference in rats. Behav Pharmacol 18: 497-506.

Smith JE, Co C, McIntosh S, Cunningham CC (2008). Chronic binge-like moderate ethanol drinking in rats results in wide- spread decreases in brain serotonin, dopamine, and norepinephrine turnover rates reversed by ethanol intake. J Neurochem 105: 2134-2155.

Smith TL, Navratilova E (1999). Increased calcium/calmodulin protein kinase activity in astrocytes chronically exposed to ethanol: influences on glutamate transport. Neurosci Lett 269: 145-148.

Spanagel R (2009). Alcoholism: a systems approach from molecular physiology to addictive behavior. Physiol Rev 89: 649-705.

Spanagel R, Hölter SM (2000). Pharmacological validation of a new animal model of alcoholism. J Neural Transm 107: 669-680.

Spanagel R, Rosenwasser AM, Schumann G, Sarkar DK (2005). Alcohol consumption and the body's biological clock. Alcohol Clin Exp Res 29: 1550-1557.

Spanagel R, Siegmund S, Cowen M, Schroff KC, Schumann G, Fiserova $\mathrm{M}$ et al (2002). The neuronal nitric oxide synthase gene is critically involved in neurobehavioral effects of alcohol. J Neurosci 22: 8676-8683.

Szumlinski KK, Lominac KD, Oleson EB, Walker JK, Mason A, Dehoff $\mathrm{MH}$ et al (2005). Homer2 is necessary for EtOH-induced neuroplasticity. J Neurosci 25: 7054-7061.

Tan SE (2002). Impairing the amphetamine conditioning in rats through the inhibition of hippocampal calcium/calmodulin-dependent protein kinase II activity. Neuropharmacology 42: 540-547.

Tan KR, Yvon C, Turiault M, Mirzabekov JJ, Doehner J, Labouebe $\mathrm{G}$ et al (2012). GABA neurons of the VTA drive conditioned place aversion. Neuron 73: 1173-1183.

Theile JW, Morikawa H, Gonzales RA, Morrisett RA (2011). GABAergic transmission modulates ethanol excitation of ventral tegmental area dopamine neurons. Neuroscience 172: 94-103.

Thielen RJ, Bare DJ, McBride WJ, Lumeng L, Li TK (2002). Ethanol-stimulated serotonin release in the ventral hippocampus: an absence of rapid tolerance for the alcohol-preferring $\mathrm{P}$ rat and insensitivity in the alcohol-nonpreferring NP rat. Pharmacol Biochem Behav 71: 111-117.

Treutlein J, Cichon S, Ridinger M, Wodarz N, Soyka M, Zill P et al (2009). Genome-wide association study of alcohol dependence. Arch Gen Psychiatry 66: 773-784.

Van Bockstaele EJ, Pickel VM (1995). GABA-containing neurons in the ventral tegmental area project to the nucleus accumbens in rat brain. Brain Res 682: 215-221.

van Zessen R, Phillips JL, Budygin EA, Stuber GD (2012). Activation of VTA GABA neurons disrupts reward consumption. Neuron 73: 1184-1194.

Virkkunen M, Linnoila M (1997). Serotonin in earlyonset alcoholism. Recent Dev Alcohol 13: 173-189.

Wang Y, Cui H, Wang W, Zhao B, Lai J (2012). The region-specific activation of $\mathrm{Ca}(2+) /$ calmodulin dependent protein kinase II and extracellular signal-regulated kinases in hippocampus following chronic alcohol exposure. Brain Res Bull 89: 191-196.

Wayman GA, Lee YS, Tokumitsu H, Silva AJ, Soderling TR (2008). Calmodulin-kinases: modulators of neuronal development and plasticity. Neuron 59: 914-931.

Xiao C, Shao XM, Olive MF, Griffin MC, Li KY, Krnjevic K et al (2009). Ethanol facilitates glutamatergic transmission to dopamine neurons in the ventral tegmental area. Neuropsychopharmacology 34: 307-318.

Xu M, Chandler LJ, Woodward JJ (2008). Ethanol inhibition of recombinant NMDA receptors is not altered by coexpression of CaMKII-alpha or CaMKII-beta. Alcohol 42: 425-432. 